\title{
O TROMPE L'OEIL, QUESTÕES PARA PENSAR O ANACRONISMO NA CONTEMPORANEIDADE
}

\section{Rosângela Miranda Cherem}

Abordarei neste trabalho uma série de fotografias de Marina Rieck Borck, artista plástica nascida em 1980 em Ilhéus na Bahia. Produzidas entre 2006 e 2007 permitem um diálogo com a pintura, fornecendo várias questões para pensar a história da arte como um procedimento realizado em camadas para onde incidem diferentes questões relacionadas ao pensamento sobre o pensamento plástico. Dispostos de modo estranho e podendo ser concebidos como fragmentos abandonados que reverberam em alguma profundeza do tempo e do espaço, os elementos que povoam suas fotos são apresentados numa composição ao mesmo tempo figurativa e abstrata. Oferecendo-se como configurações põem o olhar em funcionamento do mesmo modo que, diante das penas de um pavão ou das asas de certas borboletas, imaginamos olhos onde o que existe são ocelos.

Muito já se disse sobre o fato de que a arte, como a Filosofia, remete sempre às mesmas questões, embora também se saiba que toda obra se constitui como universo ou labirinto portátil que guarda uma profusão de incontáveis refrações e inumeráveis inquietudes numa espécie de projeção infinita. Próximo deste ponto chega-se ao entendimento de que a obra de arte não conhece história e de que seu alcance tem menos a ver com os encadeamentos cronológicos e mais com a reinstauração de enigmas, potencializados pela conexão entre descontinuidades distintas e um olhar que acolhe na particularidade do detalhe o irredutível que retorna. Assim, se a forma da linguagem é finita, os lances que permitem realizar uma espécie de pensamento-delírio não o são, sendo que é exatamente na criação como operação de esquecimento que produz uma ilusão continua e incessantemente renovada de que a arte é sempre desvio do existente e, como tal, criação de mundo.

Por sua vez, as fotografias de Marina Borck permitem aproximarse de Aby Warburg e Walter Benjamin, interlocutores favoráveis ao recurso do anacronismo e da montagem. Tal repertório encontra-se posicionado no sentido contrário ao dos manuais simplificadores da relação vida e obra ou que tomam a obra de arte como mera expressão de sintomas culturais e políticos ou meros componentes de contextos históricos e econômicos, bem como os catálogos que reduzem a obra aos estilos e escolas. Daí decorre a noção de sintoma como aquilo que interroga a imagem em sua 
relação com o tempo e interrompe o fluxo regular das coisas, tal como uma lei subterrânea que persiste no retorno de uma enfermidade, ou que se destaca como aparição de uma latência conjugando diferença e repetição, proximidade e distância, interior e exterior, imobilidade e aceleração. Enfim, nem conceito semiológico, nem conceito clínico, trata-se de uma noção operatória que recusa submissão ao tempo meramente biográfico e cronológico.

\section{A imagem como esplendor que encobre as misérias do mundo}

Recusando tanto a análise documental como a técnica, comecemos a pensar as fotografias de Marina Borck pelas camadas de poeira que acentuam a cor de ferrugem e ampliam a dramaturgia do tempo que passa projetando uma luz dourada e silenciosa sobre os objetos e ambientes. É então que podemos reconhecer os jogos de linhas e formas que não querem reapresentar o mundo, mas pensar ludicamente sua representação. Construindo um campo de cores e nuances, texturas e revestimentos inverossímeis, funcionam como testemunhas que tornam a vida natural suspeita e mostram que o esplendor não passa de um truque, enquanto a ilusão é a mais sutil das realidades.

Isto posto, é possível pensar o trompe l'oeil não como tipologia pictórica e sim como uma noção operatória, tal como o fez Deleuze acerca dos procedimentos barrocos para implicar o próprio pensamento, considerando as curvas que se lançam ao infinito e implicando em desdobramentos tanto da matéria como da alma. Armando a questão a partir de Leibniz e aproximando-a do conceito benjaminiano de alegoria, o filósofo remete à idéia de mônada como casa em cujo andar inferior caberiam os organismos e amontoados viventes, enquanto no andar de cima caberia a alma, caracterizada como o próprio espaço sem janelas e alheio à exterioridade. Reconhecendo a divisão infinita e as porções contaminadas e circunvizinhas, observa a textura porosa que opera nestes espaços, recusando a mera compartimentalização em proveito de labirintos que o constituem. Assim, diferentemente da noção renascentista da perspectiva como janela, a noção leibnizeana de mônada relaciona-se à câmara escura e à cela, onde todas as ações são internas e a luz só chega ao próprio ocupante do espaço como fenda no meio de trevas. Foi nesse mesmo regime de luzes e cores que El Greco pintou O Cristo no Jardim das Oliveiras lembrando a virtualidade incessante do teatro das matérias e destacando o acúmulo das espessuras num mundo que não possui 
existência fora delas e que se multiplica de modo cada vez mais distanciado do centro reafirmando-se como inalcançável vastidão.

Conforme Deleuze, enquanto o fundamento do perspectivismo é o sujeito que se instala num ponto de vista, sendo a extensão uma espécie de repetição continua deste ponto, na concepção barroca o movimento impõe um pathos de distância entre as mônadas. Em sua condição de empilhamento, o pensamento como a mônada, impõe um mundo infinito como modelo ótico, correspondendo a uma arquitetura da visão para um momento de crise: antes de o mundo perder seus princípios, o esplendido momento em que alguma coisa se mantém em vez do nada, em que responde à miséria do mundo com $o$ excesso de princípios. 1

Abordando aspectos que remetem tanto à suspensão das diferenças entre exterior- interior e proximidade-distância como à cenografia de luzes e sombras, Marina Borck traz para suas fotos as diversas camadas acolhidas pela memória e sedimentadas em meio aos empilhamentos do tempo. Sendo os efeitos de contigüidade produzidos por uma espécie de maquinaria do olhar funcionando às avessas, opera na tentativa de capturar a figuração informulada que salta aos olhos e a alteridade que atravessa como mascarada cujo semblante não podemos tocar e que assinala o enigma do inapreensível que a arte pode apenas tangenciar e que jamais cessa de retornar.

\section{A imagem como véu sobre um fundo que sempre retorna}

Se toda imagem é recurso através do qual as misérias do mundo e as mazelas do destino podem ser transformadas em configurações, e cuja relação com a realidade vivida é a mesma que existe entre o animal- cão e a constelação- cão, como reconhecer os fragmentos e as pertenças a que remetem as fotografias de Marina Borck? Para alcançar alguma resposta possível, melhor encarar um pouco da ficção biográfica, conforme a própria artista oferece:

As fotos são de uma empresa de esquadrias de madeira, violão e brinquedos, que começou modesta em Ijuí, interior do Ri Grande do Sul, nos idos de 1940 com meu bisavô. Em 1946 deu-se o nome que ela carrega até hoje, Rieck e Cia Ltda, cujos primeiros sócios eram Augusto Rieck e Walter Rieck, meu avô, com quem a história da fábrica se confunde. Ao longo do tempo a firma teve diversos sócios e acionistas, incluindo os nomes mais importantes da cidade, além de empregados de várias nacionalidades como alemães, letos e russos que chegaram para fazer a vida numa terra promissora (...)

${ }^{1}$ GELEUZE, Gilles. A dobra. Leibniz e o barroco. S.P.: Papirus, 2005, $2^{\text {a }}$ ed, p. 118 
As esquadrias produzidas lá eram compradas aos montes por Porto Alegre, Rio de Janeiro e Brasíla. O período áureo da fábrica se deu no período da ditadura, aproximadamente 1964, quando chegou a ter por volta de 80 funcionários, até perto da implementação da democracia, por volta de 1985, sendo que os tempos finais mesmo começaram com a morte do meu avô, no início dos anos 90 .

Um dado relevante foi a compra de um gerador de energia elétrica para a produção da fábrica: os pedidos eram muitos e a produção era rápida, mas a cidade, como ainda não era cidade exatamente, tinha períodos certos de energia elétrica durante o dia, sendo desligada em determinados horários. A fábrica, para atender a todos os pedidos, não podia parar, então meu avô comprou o primeiro gerador próprio, lembrado até hoje pelos mais antigos como um fato de suma importância para o desenvolvimento de Ijuí. O nome do gerador - de uma poética digna de dar nome a um trabalho - é Motor Estacionário de um Tempo, sendo que esse motor hoje, como a firma, está desatualizado e sem vida, largado num canto e parece ter como único destino o ferro-velho. Curiosidade: no pós-guerra, apreensivos com alguma conseqüência que a mesma poderia trazer,os habitantes consideraram aproveitar este motor para gerar energia na cidade, caso fosse necessário.

A produção de violões funcionou também enquanto meu avô ainda estava vivo, assim como a de brinquedos - caminhõezinhos e afins, tudo sempre de madeira. Cabe dizer, mais um exemplo do que se acaba, que os artesãos que faziam tais objetos estão morrendo, sem que os mais jovens queiram aprender o ofício. Seis anos depois da morte do meu avô meus pais resolveram voltar para o Ijuí na tentativa de revitalizar a fábrica. Mas ela já estava profundamente sucateada e decaída e hoje funciona sem muitas perspectivas. Ainda em escombros, é sustentada provavelmente pela última geração, no caso meu pai e minha mãe, descendente direta do vô Walter. No final deste ano fará 10 anos que viemos para cá por conta disso.

\section{A imagem como máquina para produzir delírio}

Reconhecendo os dados biográficos apresentados pela fotógrafa tal como o fez o protagonista de Bioy Casares em $A$ invenção de Morel, que aproximou as imagens remotas ao tempo-espaço vivido e manteve com as projeções uma estranha relação de intimidade afetiva, detenhamo-nos um pouco mais sobre aquilo que se torna alvo do olhar fotográfico. Observemos o caráter ornamental das imagens, trabalhadas por uma espécie de exímio joalheiro que produz algo tão minucioso e secreto que só pode ser percebido raramente e através de um relance ou conjunção. É então que podemos constatar que o trompe l'oeil comparece nas fotos de Marina Borck formulado primeiro pelos termos pictóricos, ou seja, pelos efeitos de luzes e sombras, cores e texturas, linhas e formas, figurações e abstrações materializadas através de vitrais e grades, superfícies e naturezas-mortas. Depois porque esta encenação que parece artifício e ornamento nada mais é do que a própria cenografia das coisas depositadas naturalmente no ambiente de uma fábrica em decomposição. Por último porque as coisas registradas e os problemas pictóricos a que remetem desobedecem aos registros biográficos, ultrapassando-os.

Por sua vez, numa perspectiva eucrônica da história da arte, o trompe l'oeil se coloca como uma tipologia ou abordagem da pintura caracterizada pela invasão do espaço do espectador, simulando uma 
verdade documental enfatizada pela fiel representação da realidade. Assim, sustentada pelos truques do sombreado e das formas decupadas, confundindo o próximo e o distante, o interior e o exterior, o sombrio e o luminoso, a superfície biplanar se torna dotada de carnalidade, constituindo-se numa espécie de espelho que projeta uma hiper-presença palpável da coisa ausente, registro de uma materialidade que se afirma mediante o desfalecimento da realidade e permite pensar o que emerge na sua condição enganosa. ${ }^{2}$

Todavia, para compreender as implicações deste procedimento é preciso ultrapassar as questões tipológicas, tentando considerar como se constitui o efeito de sentido do real. Um primeiro ponto desta reflexão remete à relação tempo-imagem, a qual só se torna possível numa construção com a memória e sua constante apropriação de tempos descontínuos e heterogêneos. Desdobramento deste ponto, a imagem desponta como mistério figural, cujo recurso do anacronismo se torna infenso aos procedimentos iconológicos e historicistas, reconhecendo menos a figuração e mais a figurabilidade como o fundo a que as figuras enviam.

Nem realismo, nem mero ilusionismo, cujo efeito hipnótico hipertrofia o engano dos sentidos, diferentemente do espaço pictórico concebido pelo olhar renascentista como evasão e cuja precisão racional se sustenta na busca mais perfeita de re-apresentação do mundo, o trompe l'oeil invade produz um rasgo que alcança e atinge aquele que se encontra diante da obra. ${ }^{3}$ Através de uma cenografia que simula a disposição casual das coisas e seres, a ilusão se apresenta não como um atributo da imagem artística, mas como mais persistente e tangível das realidades, artifício ou recurso pelo qual o que nos circunda se torna familiar e se humaniza. Assim, as fotografias de Marina são desdobramentos da pintura e suas reflexões sobre a matéria do mundo. Ironizando o excesso de realidade e ultrapassando a presença redutora das coisas para alcançá-las naquilo que volta como inquietante e longínqua aparição, sua poética acaba por problematizar aquilo que, ao mesmo tempo, funda e solapa o fenômeno do olhar.

\footnotetext{
2 BAUDRILLARD, Jean. A Arte da desaparição. R.J.: Ed. UFRJ / N-Imagem, 1997. Capítulo I.

3 MILMAN, Miriam. Le Trompe-L'oeil. Les illusiones de la réalité. Genève: Suisse. Editions d'Art Albert Skira S.A., 1994.
} 
Cumprindo a função de véu que nem cobre nem descobre mas apenas encobre, remetem aquilo que Lacan chamou de empuxo, ou seja, o jogo infinito entre o olhar e a visão. E posto que ver é devolver, é dar um olhar, ${ }^{4}$ é precisamente nesta articulação que podemos nos pensar como seres olhados no espetáculo do mundo. ${ }^{5}$ Reviravolta do olhar, que acolhe o ver-se vendo-se e implica num olhar imaginado por mim no campo do outro.

A esse propósito, é o próprio psicanalista quem lembra a célebre disputa entre Zeuxis e Parrásio, narrada no século I d.C. pelo enciclopedista Plínio, o velho: entre a perfeição naturalista das uvas pintadas que confundiam os pássaros e a ilusão da cortina cobrindo uma parede, o crédito foi para o artista que fez o olhar triunfar sobre o olho. Ao pintar o véu, Parrásio demonstrou que o olhar sempre busca um através, um fundo marcando a pintura como um jogo de opacidade, que situa no quadro um lado de fora, oferecendo-se como pastagem ao olho e buscando aquilo que ultrapassa o campo da visão. Enquanto um enganou animais, o outro confundiu o próprio artista oponente, condensando neste episódio o fato de que é sempre um mais-além que se busca, sendo que, na ilusão de reencontrar a coisa como paradoxo da criação, o artista pode apenas contornar aquilo que jamais alcança e nada mais faz do que figurar a experiência do vazio a partir de desarranjos e desencontros.

Observando atentamente aqueles objetos, compreende-se que a perspectiva não é o oposto mas parte constitutiva do trompe l'oeil, assinalando a ilusão não apenas como um atributo da pintura mas como uma realidade que ultrapassa a presença das coisas para remetê-la à condição de aparição mais longínqua. Simulando um tratamento e uma dimensão mais abstrata, estas superfícies registram uma dramaturgia do invisível obtida pela eficácia da imagem, apresentando-se como um fenômeno paradoxal da visão alcançado como delírio. ${ }^{6}$ Portadoras de uma exatidão que atinge aquele que para elas se volta, as imagens desfazem a evidência do mundo através do recurso de uma mutação que embaralha os sentidos, especialmente produzindo uma confusão do código visual, onde a centralidade retiniana é substituída pela realidade táctil, desdobrando um jogo de casualidade que se afirma pelos objetos e seres que servem para

\footnotetext{
${ }^{4}$ MARIN, Louis. Sublime Poussim. S.P.: Edusp, 2000, p. 165.

${ }^{5}$ LACAN, Jacques. O seminário. Livro 11, os quatro conceitos da psicanálise.R.J.:Ed. Zahar,1998, 2a Ed. p.76.

${ }^{6}$ DIDI-HUBERMAN,George. Devant l'image. Paris: Lês Editions de Minuit. 1990, capítulo 4.
} 
fazer pensar a existência, através dos vestígios por ela deixados e que a elas remetem.

Questão que, ao mesmo tempo, funda e solapa o fenômeno do olhar, emoldurando ou preenchendo o vazio dos corpos e cenas, as imagens ali contidas parecem dirigir-se intimamente a quem para elas se volta, ao mesmo tempo em que remetem ao vazio, ao exterior e ao indefinido, fundo sórdido sobre o qual ela continua afirmando as coisas em seu desaparecimento. ${ }^{7}$ Assim o que elas preenchem refere-se a uma ausência indeterminada da forma, ou seja, a uma sorte de humanização do informe, retirando a obscuridade do destino em sua essência, que é a de ser sombra.

Pensemos especialmente as cenas que afirmam a dimensão presença-ausência inapreensível e inatural da imagem, assinalando os restos de um objeto como se fosse um cadáver na calma absoluta do que encontrou seu lugar , ao mesmo tempo em que suspende a relação absoluta com ele. Aqui e em parte alguma, eis o lugar do morto que se une ao fundo, situando num antemundo, aquém- além eterno onde a ação está impossibilitada de voltar à superfície do que restou. Imponente e soberbo, ser que triunfa e se exprime com o recurso inacessível do longínquo, o corpo morto surge como imagem da aparição original em sua mais elementar e perturbadora estranheza, remetendo ao fato de que a fixidez da imagem, como a do cadáver, é a posição do que permanece porque lhe falta lugar. ${ }^{9}$

Transportado para um local situável e simbólico, o despojo passa a pertencer também a um lugar impessoal e neutro, confirmando-se como aquilo com que os viventes tentam contornar a mais inescapável condição: intima é a imagem porque ela faz de nossa intimidade uma potência externa a que nos submetemos passivamente: fora de nós, no recuo do mundo que ela provoca, situa-se desgarrada e brilhante, a profundidade de nossas paixões. ${ }^{10}$

Todavia, em sua captura fotográfica bastante singular e problematizando a relação da arte contemporânea com o cadáver, não é o corpo dilacerado e em decomposição que Marina Borck apresenta e sim os próprios objetos que se apresentam como máscara, encenando aquilo que Callois registrou como psicastenia, distúrbio da percepção espacial que poderia ser sintetizado pela afirmação sei onde estou, mas não me sinto no lugar

\footnotetext{
${ }^{7}$ BLANCHOT, Maurice. O espaço literário. R.J.: Ed. Rocco, 1987, p.256

${ }^{8}$ Ibidem, p. 258

${ }^{9}$ Ibidem, p. 260

${ }^{10}$ Ibidem, p. 263.
} 
onde me encontro. ${ }^{11}$ Nesta tendência à imobilidade e ao inorgânico o que se confirma é uma economia de dispêndio, sutil armadilha e veículo de fascinação, cujos elementos mais atraentes acabam por agir como força final, resultando numa espécie de uniformidade ou anulação que conduz ao inanimado.

${ }^{11}$ CAILLOIS, Roger. Mimetismo e psicastenia legendária. Revista Che Voui, ano 1, Cooperativa Cultural Jacques Lacan, Porto Alegre: 1986. 

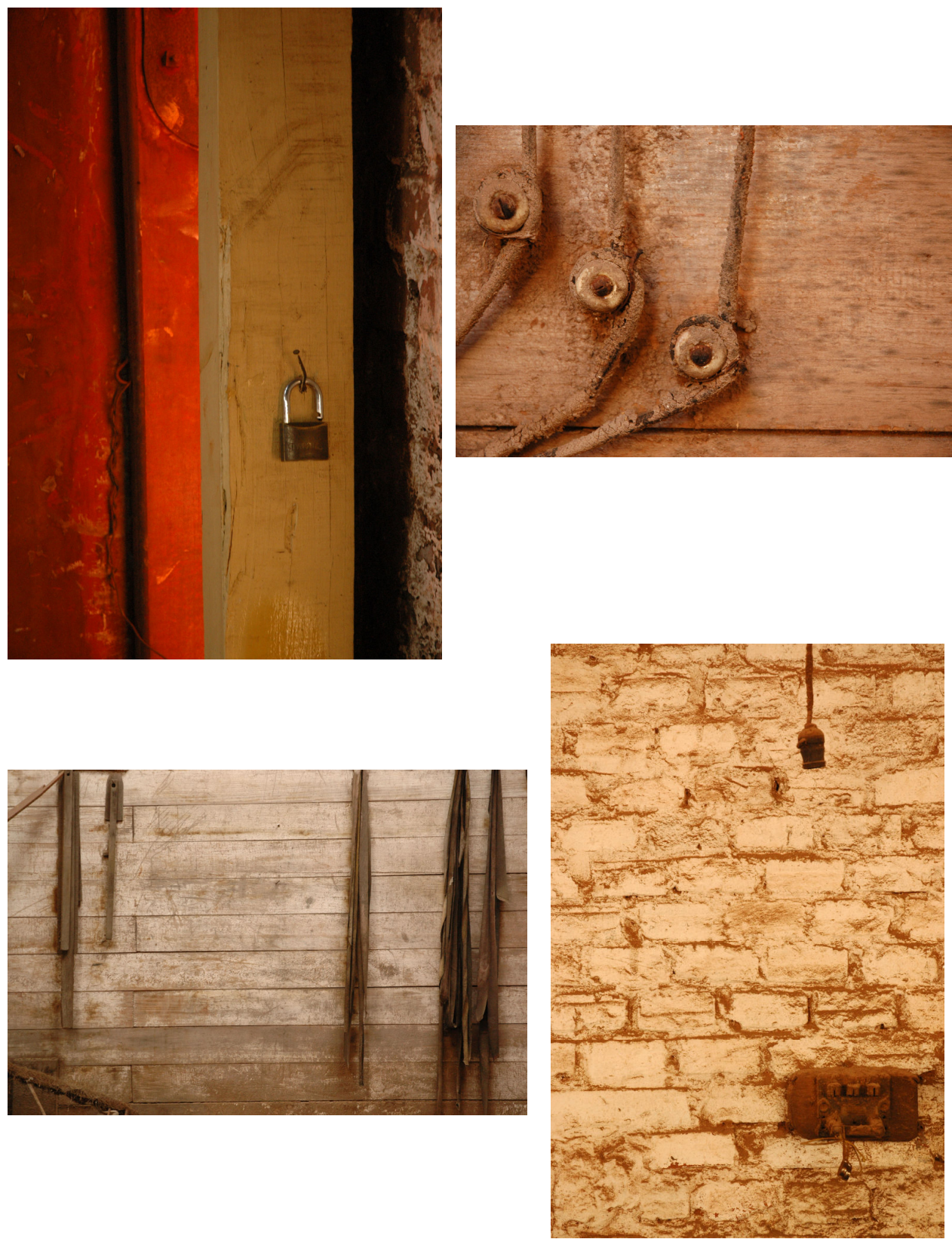